Article

\title{
Cadmium Uptake, In Vivo Metastasis and Subcellular Environmental Response of Five Wetland Plants Using DFT Method
}

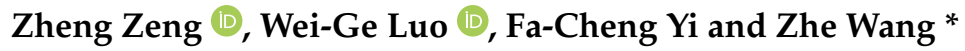 \\ College of Environment and Resources, Southwest University of Science and Technology, \\ Mianyang 621010, China; zengzheng@vip.163.com (Z.Z.); comeluoweige@163.com (W.-G.L.); \\ yfc66@163.com (F.-C.Y.) \\ * Correspondence: wz2004@126.com
}

check for updates

Citation: Zeng, Z.; Luo, W.-G.; Yi, F.-C.; Wang, Z. Cadmium Uptake, In Vivo Metastasis and Subcellular Environmental Response of Five Wetland Plants Using DFT Method. Sustainability 2021, 13, 7872. https:// doi.org/10.3390/su13147872

Academic Editor: Gera Troisi

Received: 14 June 2021

Accepted: 7 July 2021

Published: 14 July 2021

Publisher's Note: MDPI stays neutral with regard to jurisdictional claims in published maps and institutional affiliations.

Copyright: (c) 2021 by the authors. Licensee MDPI, Basel, Switzerland. This article is an open access article distributed under the terms and conditions of the Creative Commons Attribution (CC BY) license (https:/ / creativecommons.org/licenses/by/ $4.0 /)$.

\begin{abstract}
The main purpose of this study is to analyze whether $\mathrm{Cd}^{2+}$ affects the absorption of $\mathrm{Ca}^{2+}$ and $\mathrm{Fe}^{2+}$ by the roots of five wetland plants and the toxic mechanism of cadmium on the subcellular structure. Five wetland plant samples were collected from the constructed wetland in the upper reaches of the Yangtze River. Based on the experiment and density function theory (DFT), we measured the $\mathrm{Cd}^{2+}$ content in the root, stem, and leaf, the morphological dimensions of plants, and in the subcellular structure the electronic activity of Cd compound was calculated to describe the stability and activity of the products. In general, Zephyranthes candida, Cynodon dactylon, Arundo donax, and Pontederia cordata have distinct cadmium uptake characteristics, while Phragmites communis does not. The results indicated tolerance to cadmium in all but Phragmites communis, which was due to cadmium distribution through the process of transpiration and a mechanical interception. The simulation results showed that $\mathrm{Cd}^{2+}$ imposed no obvious inhibition on the absorption of $\mathrm{Ca}^{2+}$ and $\mathrm{Fe}^{2+}$ in plants, as the energy barrier of the process is about $1-3 \mathrm{eV} \cdot \mathrm{Cd}^{2+}$ could improve the amount of pyruvate and glucose by $30 \%$ via spd orbital hybridization, making them more chemically reactive. At the same time, $\mathrm{Cd}^{2+}$ could replace $\mathrm{Mg}^{2+}$ in chlorophyll through a copper substitution reaction, making the electron energy of chlorophyll more concentrated. As a result, the valence-band electron at $-40 \mathrm{eV}$ was vacant. In conclusion, we determined that $\mathrm{Cd}^{2+}$ has no obvious inhibitory effect on $\mathrm{Ca}^{2+}$ and $\mathrm{Fe}^{2+}$ in root absorption and that $\mathrm{Cd}^{2+}$ could affect the properties of compounds of the subcellular structure and thus produce physiological toxicity.
\end{abstract}

Keywords: wetland plants; density functional theory (DFT); cadmium enrichment factor; cadmium transport coefficient; subcellular structure

\section{Introduction}

Although cadmium is not an essential element for plant growth and development, it can be absorbed by plants through the root system and accumulate in the plant. The accumulation of cadmium would contaminate the food chain and threaten higher-level consumers and human beings [1-3]. Furthermore, cadmium is biologically toxic, as it can inhibit plant cell growth [4] and oxidative phosphorylation [5], as well as cause oxidative stress [6], affect photosynthesis [7], and damage subcellular structure and activity [8-10]. A previous work [11] showed that the upper reaches of the Tuojiang River in Southwest China was polluted by cadmium, while the water quality in the lower reaches was in good condition. The cadmium content in the upper reaches was $0.0909 \mathrm{mg} \cdot \mathrm{L}^{-1}$, which greatly exceeded the requirements of China's national water quality standard of $0.005 \mathrm{mg} \cdot \mathrm{L}^{-1}$. It could be inferred that the constructed wetlands along the Tuojiang River removed a large amount of available cadmium. Although a previous work [12] studied the role of constructed wetland in cadmium removal, in order to reveal the pathways of cadmium removal it is still of great importance to study the absorption and transport of cadmium by wetland plants. 
Generally, cadmium uptake by plants involves the following processes: (1) root uptake, (2) transport from root to stem, and (3) transport from stem to leaf. The factors affecting cadmium uptake by roots mainly include soil $\mathrm{pH}$, total soil cadmium, soil organic matter, root exudates, and tufted microbial exudates. As proposed by Teisser in 1977, cadmium exists in the environment in different states, such as an exchangeable state, a carbonate state, an Fe/Mn oxides state, an organic/sulfide state, and a residual state [13]. The exchangeable state generally refers to water-soluble cadmium salt, which has the strongest bioavailability. A high exchangeable cadmium content could be expected in soils with high total cadmium and lower $\mathrm{pH}$ [14]. Generally, the soil organic matter content leads to an increase in exchangeable cadmium content [15]. However, there is also evidence that increased soil organic matter content can lead to a decrease in available cadmium content [16]. Available cadmium content is mainly determined by the nature of soil organic matter [17]. For example, organic acids secreted by plant roots are beneficial for the increased availability of cadmium in soil $[18,19]$. The presence of tartaric acid can increase the content of available cadmium by 1.4-6.9 times [20]. Normal soil organic acids, including ethylenediamine tetra-acetic acid, citric acid, malic acid, and oxalic acid, can increase the proportion of available cadmium to total cadmium in soil [21,22].

Root exudates can increase the competitive absorption of ions in the environment, consequently promoting or inhibiting cadmium uptake. A study has shown that the transport efficiency of cadmium can be improved by the competitive occupation of calcium and iron absorption sites within the root system [23]. At the same time, research has also shown that the absorption capacity of iron and cadmium changes synchronously, indicating no competitive absorption [24]. Similar conditions have been reported for other essential metals, for instance, in wheat experiments it has been proven that there is no competitive absorption of zinc and cadmium [25]. In 2020, a study that showed the active addition of nutrients needed for rice, iron, and manganese found that both elements inhibited cadmium absorption by 9-65\% [26]. However, their conclusions explain the inhibition from the aspect of transporter proteins rather than the absorption sites of root exudates. A review claims the divalent cations have the similar two stages of uptake process, the apoplastic and symplastic pathways [27]. Some results even found Fe could facilitate Cd uptake [28]. For the apoplastic pathway, the divalent cations compete for shared organic acid adsorption sites. Considering the distribution between different ions, the specific absorption energy and energy of complex can be calculated using density functional theory (DFT) to determine which heavy metal possesses an absorption advantage.

Generally, cadmium hyper-accumulators usually have developed roots and dense root hairs [29]. For example, a cadmium absorption capacity of $1800 \mathrm{mg} \cdot \mathrm{kg}^{-1}$ was observed for Thlaspi caerulescens. The transport efficiency from root to stem is an important feature of hyper-accumulators, while the accumulation capacity of organic acids in plants determines the maximum accumulation amount of cadmium [30]. The xylem is the channel for cadmium transport from root to stem, with transpiration and root pressure dictating the transport rate of the process [31]. The transport of cadmium in the xylem and the accumulation of cadmium in the stem were accelerated under stronger transpiration and higher root pressure. When abscisic acid was used to inhibit the transpiration of plants, it was found that the concentration of cadmium in aboveground parts of plants decreased [32]. Once cadmium is accumulated in the stem, with the development of plants, cadmium will enter the phloem and be redistributed into various organs of the plants [33,34]. As the phloem is connected to important organs such as the flowers, leaves, and fruits, the presence of cadmium in the phloem could result in subcellular structural toxicity. Cadmium accumulation in subcellular structures mainly resulted in variations in morphological and physiological processes. Reduction in dry matter yield and leaf area shrinkage were reported [35-37] for morphological variations, and chlorophyll was reduced [38], photosynthesis and respiration were inhibited [39], and growth was slowed [40]. Cd uptake in basil seeds delayed the germination for 3-6 days [36]. High concentration of $\mathrm{Cd}$ contributes to the delayed growth rate, and it was speculated that $\mathrm{Cd}$ inhibits the absorption and transport of wa- 
ter [41]. Tomato [42] and cucumber [43] have a decreased photosynthetic performance duo to $\mathrm{Cd}$ uptake. For respiration, there is proof $\mathrm{Cd}$ could transport electrons to the electron donor [44]; therefore, it could seriously impede the normal respiration. Therein, some reaction products could trap cadmium in organelles, persistently interfering with normal physiological processes [45]. Similarly, the subcellular structure could affect the form and transport of cadmium. For example, the vacuoles of some cadmium hyper-accumulation plants can trap cadmium ions with malic acid [46]. Therefore, it is of great importance to reveal the active forms of the main organic compounds and cadmium in subcellular structures. To simulate the effect of cadmium ions on the subcellular structure, chlorophyll $\mathrm{A}$ and $\mathrm{B}$ are used to represent the chlorophyll environment, while glucose and pyruvate are used to represent the mitochondrial environment.

In order to further describe the interactions and performance changes of cadmium ions with plant metabolites, subcellular structure, and main components, density functional theory (DFT) based on quantum chemistry was used to solve the Schrodinger equation of the multi-electron system. Density functional theory (DFT) not only simplifies the Schrodinger equation of multi-particle system by using the Born-Oppenheimer approximation [47] (the terms of electron and atom nucleus motions are treated separately) and the Hartree-Fock approximation [48] (mean-field approximation), it also takes the Coulomb interactions between electrons into account. All the particles in the multi-electron system are regarded as identical particles, and the electron density was used as the variable of the energy functional theory for the calculation of the ground-state energy of the system so as to describe the physical properties of the ground state of atoms, molecules, and solids, and the relationships between the electronic structure and energy of the system. As a result, Hohenberg and Kohn proposed the theory of inhomogeneous electron gas, namely the famous Hartree-Fock approximation [49], and the energy of the multi-particle system is the function of electron number density. To further determine the exchange correlation of the energy functional and solve the energy functional, Kohn and sham proposed the Kohn-Sham (KS) equation [50]. Compared with the Hartree-Fock approximation, the Kohn-Sham equation added two further terms of electron exchange interaction and electron correlation interactions. In the process of solving the electron density and energy using the KS equation, it is necessary to use the self-consistent field (SCF) method to make the calculated value converge below the set value. According to the electron probability density and energy after convergence, the ground-state and related properties of the system are deduced [51]. However, the Kohn-Sham equation only involved the electron probability density and kinetic-energy functional in the electron energy term, while further considerations of the potential energy term between electrons were missing. Therefore, it is necessary to further deal with the cross-linking energy between electrons. Currently, the commonly used approximation methods included local density approximation (LDA) [52], generalized gradient approximation (GGA) [53], and local spin density approximation (LSDA) [54]. Compared with LDA, GGA added the density gradient term of electron density between adjacent elements on the basis of LDA, which overcame the exchangecorrelation energy of the non-uniform electron system. LDA is more suitable for calculating the metal system; therefore, GGA was selected for approximate calculation in this study. At present, the simulation calculation based on density functional theory has been widely used in biology [55], materials [56], minerals [57-59], and other fields.

Cadmium and other divalent ions are transported through the xylem and phloem in the form of free ions or organic complexes. Therefore, we used both organic acid complex cadmium [60] and free ions to simulate the biological toxicity of cadmium. In this work, both experiments and simulation calculations were used. Firstly, we verified the absorption of cadmium by the selected wetland plants through experiments and then calculated the cadmium enrichment coefficient, rhizome transport coefficient, and stem leaf transport coefficient of the plant to indicate the difference in absorption transport between plants. Secondly, the competitive absorption of cadmium, calcium, and iron on organic acids was then calculated by DFT to reveal the competitive advantage of cadmium. The biological 
toxicity of cadmium was simulated according to the differential charge density and density of states (DOS) of different subcellular structures.

\section{Materials and Methods}

\subsection{Data Acquisition}

Five kinds of plants, namely, Zephyranthes candida, Cynodon dactylon, Arundo donax, Phragmites communis, and Pontederia cordata, were collected from a constructed wetland park in the upper reaches of the Yangtze River. According to the ecological characteristics of plants, the plants were cut into three parts of root, stem, and leaf. All samples were ground to powder (up to a mesh size of 100). The sample powder was divided into two parts. One part of the powder was directly observed by scanning electron microscopy (SEM, TM4000, Hitachi, Tokyo, Japan), and the distribution of cadmium in plants was analyzed by energy dispersive spectroscopy (EDS, TM4000, Hitachi, Tokyo, Japan) to judge the presence of cadmium in the plants directly. The other part of the sample powder was digested by nitric acid hydrogen peroxide to get a clear solution, and the specific content of cadmium in different parts of the samples was determined by inductively coupled plasma atomic emission spectrometry (ICP-OES, ICAP6500, Thermo Fisher, Waltham, MA, USA).

In order to quantify the absorption capacity of different plants for cadmium from the environment and transport cadmium within the plant body, the biological concentration function (BCF) and transport function (TF) were calculated by the following formula:

$$
\begin{gathered}
\mathrm{BCF}=\text { total cadmium in plant/environmental cadmium content } \\
\mathrm{TF} 1=\text { stem cadmium content } / \text { root cadmium content } \\
\mathrm{T} 2=\mathrm{CD} \text { content in leaves } / \mathrm{CD} \text { content in stems }
\end{gathered}
$$

where:

$\mathrm{TF} 1$ = transport coefficient of rhizome;

$\mathrm{T} 2$ = stem leaf transport coefficient.

\subsection{Calculation Details}

The calculation of quantum chemistry based on density functional theory was done using the Material Studio 7.0 software (Accelrys Software InciSan Diego, California, USA). Molecular models of some common root metabolites, including citric acid, oxalic acid, tartaric acid, malic acid, succinic acid, and fumaric acid (as shown in Figure 1) [61,62], were established for the five experimental plants. The molecular models were established based on the main substances in the different subcellular structures. For example, chlorophyll A and chlorophyll B represent the chloroplast environment, while glucose and pyruvate represent the mitochondrial environment. The structure optimization and properties calculation of all the models was performed by means of quantum mechanical calculations based on DFT using the GGA (generalized gradient approximation) and PBE (Perdew-Burke-Ernzerhof) exchange-correlation functional [57-59]. The CASTEP was used for structure optimization and property calculations. The highly accurate full-potential projector-augmented-wave (PAW) method with ultrasoft pseudopotentials was used to describe the electron-ion interactions in the valence-band region. Brillouin-zone integrations were calculated with a gamma-centered $3 \times 3 \times 3$ Monkhorst-Pack k-point mesh. The convergence criteria for the energy, maximum force, maximum displacement, and SCF tolerance were set as $1.0 \times 10^{-5} \mathrm{eV} /$ atom, $0.01 \mathrm{eV} / \mathrm{A}, 1.0 \times 10^{-4} \AA$, and $1.0 \times 10^{-4} \mathrm{eV} /$ atom, respectively. 


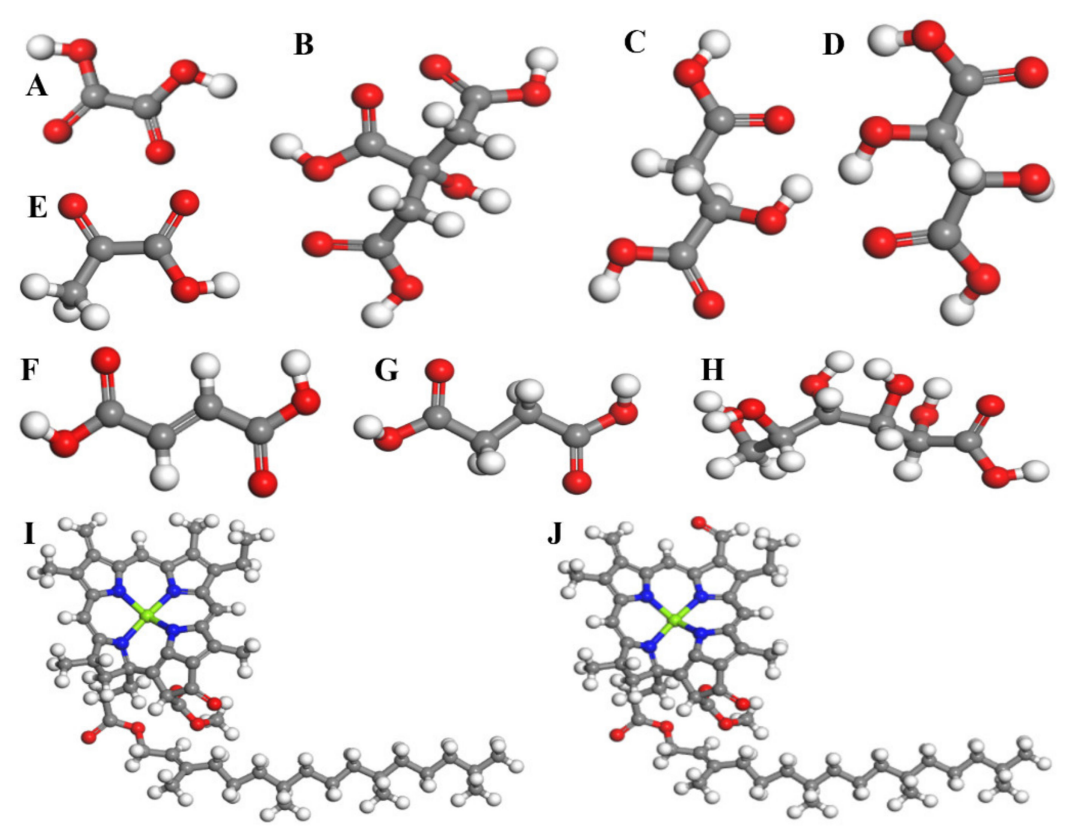

Figure 1. (A) oxalic acid, (B) citric acid, (C) malic acid, (D) tartaric acid, (E) pyruvic acid, (F) fumaric acid, (G) succinic acid, (H) glucose, (I) chlorophyll A, and (J) chlorophyll B.

\section{Results and Discussion}

\subsection{Competitive Absorption of $\mathrm{Cd}, \mathrm{Ca}, \mathrm{Zn}$ and Fe on Root Exudates}

The six kinds of organic acids secreted by roots, metal chloride $(\mathrm{Cd}, \mathrm{Ca}$, and $\mathrm{Fe})$ in soil environment, and the configuration energy of corresponding complexes were calculated by CASTEP, as shown in Table 1 . It should be noted that the calculated final energy is not of practical significance but only represents the value of the optimized configuration. Therefore, it is necessary to calculate the reaction energy barrier through the final energy of each molecular configuration (i.e., the amount of energy change in the reaction process) in order to measure the difficulty of different reactions. The formula is as follows:

$$
E_{b}=E_{c}-\left(E_{o}+E_{m}\right)
$$

where $E_{b}$ is the reaction barrier, $E_{c}$ is the final energy of organometallic complexes, $E_{m}$ is the final energy of metal salt, and $E_{o}$ is the final energy of organic acids.

Table 1. Energy of organic compounds and organometallic complexes.

\begin{tabular}{|c|c|c|c|c|c|c|c|}
\hline Metal Form & $E_{m}(e V)$ & Organic Acid & $\begin{array}{c}\mathrm{E}_{\mathbf{o}} \\
(\mathrm{eV})\end{array}$ & $\begin{array}{l}\text { Complex } \\
\text { Compound }\end{array}$ & $\begin{array}{c}E_{c} \\
(e V)\end{array}$ & $\begin{array}{c}E_{b} \\
(e V)\end{array}$ & $\begin{array}{l}\text { Absorption } \\
\text { Sequence }\end{array}$ \\
\hline \multirow{4}{*}{$\mathrm{CdCl}_{2}$} & \multirow{4}{*}{-2101.78} & \multirow{4}{*}{ Oxalate } & \multirow{4}{*}{-2086.82} & $\mathrm{Cd}$ & -3336.65 & 851.95 & \multirow{4}{*}{$\mathrm{Fe}>\mathrm{Ca}>\mathrm{Cd}$} \\
\hline & & & & $\mathrm{Ca}$ & -3058.06 & 850.5 & \\
\hline & & & & $\mathrm{Fe}$ & -2916.99 & 849.3 & \\
\hline & & & & $\mathrm{Cd}$ & -5360.01 & 854.23 & \\
\hline \multirow[t]{3}{*}{$\mathrm{CaCl}_{2}$} & \multirow{3}{*}{-1821.74} & \multirow[t]{3}{*}{ Citric acid } & \multirow{3}{*}{-4112.46} & $\mathrm{Ca}$ & -5080.93 & 853.27 & \multirow[t]{3}{*}{$\mathrm{Ca}>\mathrm{Cd}>\mathrm{Fe}$} \\
\hline & & & & $\mathrm{Fe}$ & -4935.89 & 856.04 & \\
\hline & & & & $\mathrm{Cd}$ & -4144.49 & 854.79 & \\
\hline \multirow[t]{11}{*}{$\mathrm{FeCl}_{2}$} & \multirow[t]{11}{*}{-1679.47} & \multirow[t]{3}{*}{ Malic acid } & \multirow[t]{3}{*}{-2897.50} & $\mathrm{Ca}$ & -3865.79 & 853.45 & \multirow[t]{3}{*}{$\mathrm{Ca}>\mathrm{Cd}>\mathrm{Fe}$} \\
\hline & & & & $\mathrm{Fe}$ & -3722.80 & 854.17 & \\
\hline & & & & $\mathrm{Cd}$ & -4554.81 & 874.2 & \\
\hline & & \multirow[t]{3}{*}{ Tartaric acid } & \multirow[t]{3}{*}{-3327.23} & $\mathrm{Ca}$ & -4274.29 & 874.68 & \multirow[t]{3}{*}{$\mathrm{Fe}>\mathrm{Cd}>\mathrm{Ca}$} \\
\hline & & & & $\mathrm{Fe}$ & -4147.74 & 858.96 & \\
\hline & & & & $\mathrm{Cd}$ & -3670.01 & 855.75 & \\
\hline & & \multirow[t]{3}{*}{ Fumaric acid } & \multirow[t]{3}{*}{-2423.98} & $\mathrm{Ca}$ & -3391.84 & 853.88 & \multirow[t]{3}{*}{$\mathrm{Fe}>\mathrm{Ca}>\mathrm{Cd}$} \\
\hline & & & & $\mathrm{Fe}$ & -3251.39 & 852.06 & \\
\hline & & & & $\mathrm{Cd}$ & -3704.20 & 854.78 & \\
\hline & & \multirow[t]{2}{*}{ Succinic acid } & \multirow[t]{2}{*}{-2457.20} & $\mathrm{Ca}$ & -3423.22 & 855.72 & \multirow[t]{2}{*}{$\mathrm{Cd}>\mathrm{Fe}>\mathrm{Ca}$} \\
\hline & & & & $\mathrm{Fe}$ & -3281.53 & 855.14 & \\
\hline
\end{tabular}


When cadmium and plant essential elements, calcium and iron, coexist in the environment, the absorption of the three elements is relatively average (Table 1). It was found that $\mathrm{Cd}^{2+}$ only occupied the absorption sites of $\mathrm{Ca}^{2+}$ and $\mathrm{Fe}^{2+}$ on succinic acid, while the absorption advantage of $\mathrm{Cd}^{2+}$ on malic acid and citric acid was not obvious. On the contrary, the absorption of $\mathrm{Fe}^{2+}$ and $\mathrm{Ca}^{2+}$ on oxalic acid, tartaric acid, and fumaric acid was hardly affected by $\mathrm{Cd}^{2+}$. The reaction energy barrier of calcium citrate is $1 \mathrm{eV}$ lower than that of cadmium citrate; thus, calcium ion has a weak absorption advantage over cadmium. Similarly, for the absorption on malic acid, calcium malate had the lowest energy barrier, while the energy barrier for cadmium and iron absorption is similar. Thus, the latter two have no obvious absorption advantage. The reaction energy barrier of ferric oxalate is about $3 \mathrm{eV}$ lower than that of cadmium oxalate, indicating that free ferrous ions have a greater absorption advantage over cadmium element. It is worth noting that the energy barrier of $\mathrm{Fe}^{2+}$ absorption on tartaric acid is about $20 \mathrm{eV}$ lower than that of cadmium and calcium (Table 1). According to the bond-valence theory, calcium $\left(3 s^{2} 3 p^{6}\right)$ and cadmium $\left(4 \mathrm{~d}^{10} 5 \mathrm{~s}^{2}\right)$ are in a stable energy state, while iron $\left(3 \mathrm{~d}^{6} 4 \mathrm{~s}^{2}\right)$ has four single-spin electrons in the $\mathrm{d}$ orbit of the sub-level, which is in an unstable energy state. The two hydroxyl groups in the tartaric acid molecule could more effectively excite the outer electrons of iron than the stable outer electrons of calcium and cadmium.

This can also explain why the energy barrier difference is quite small for the absorption of three kinds of ions on other organic acids. As with oxalic acid, citric acid, and malic acid, only one hydroxyl group exists in the molecular structure, which is insufficient to excite the iron $d$-orbital. No hydroxyl groups exist in fumaric acid and succinic acid: the $\mathrm{C}=\mathrm{C}$ double bond in these two acids can only reduce the energy of the molecule itself, inhibiting the self-reaction activity, which leads to a higher reaction barrier. According to the structural formula of citric acid, the energy of citric acid is higher than that of tartaric acid $(4112.46>3327.23)$. The reason for its higher energy is the presence of three carboxyl groups, indicating more unstable carboxyl hydroxyl groups. The capability to ionize protons indicated higher energy in the acid. Therefore, the excitation effect on the $d$-level single electron of iron may not be strong despite its higher energy. From the calculation results, most of the secreted acids can absorb cadmium and essential elements like calcium and iron simultaneously. However, organic acids secreted by plant roots notably have the possibility to decrease the absorption of essential elements due to cadmium absorption.

\subsection{Cadmium Transport among Roots, Stems and Leaves}

After entering the plant roots, cadmium will be transported to all parts of the plant. By analyzing the cadmium content in various parts of the plant, we can know whether the plant has defense measures against cadmium. In other words, the cadmium distribution and content within the plant body could indicate the ability of cadmium-tolerant plants to treat cadmium-contaminated soil or water bodies. It may also serve as a monitoring indicator for cadmium contamination of soil or water bodies. As shown in Figure 2, cadmium was present in all five plants. The absorption capacity for cadmium in the plants was in the order of $Z$. candida $>P$. cordata $>C$. dactylon $=A$. donax $>$ P. communis (Table 2 ). The BCF of $P$. communis is less than 1, indicating that the plant is not an effective cadmium enrichment plant.

Plants with a strong stem are usually able to intercept cadmium. In other words, the stem could intercept cadmium in the gap between the cell wall and cytoplasm by mechanical blocking [63], which inhibits the transportation of cadmium in the plant body. It could be proven that the cadmium content in the stem of $C$. dactylon and P. communis was higher than that in the root and leaf. The diameters of the leaf and stem of the five wetland plants are presented in Table 3. The cadmium content in leaves of $C$. dactylon (0.008 ppm) and P. communis (0.006 ppm) was very low, which could be attributed to the strong interception by the stem. The stems of $C$. dactylon were quite thin. Since most of the plants are grown underground, the phloem tissues are very thick and the transpiration rate is weak; thus, the cadmium uptake of $C$. dactylon is large and the upward 
transport is inhibited. Although A. donax has strong stems, cadmium is mainly concentrated in its leaves. This phenomenon could be ascribed to its super-large leaf. The strong transpiration by the leaves could drive the cadmium intercepted by the stems towards leaves again. Compared to $A$. donax, cadmium was evenly distributed in the stems and leaves of $P$. cordata. The leaf sizes of $P$. cordata are about half of $A$. donax, making the cadmium transportation rate within the plants similar to that of transpiration. Thus, the distribution of $\mathrm{Cd}$ in the stem and leaf was more uniform. Therefore, the transportation of cadmium in plants mainly depends on transpiration and mechanical interception of stem cell structure. Meanwhile, the tolerance of plants to cadmium can also be measured by the transport coefficient. As is well known, plants have evolved many new structures in the stem [47] to inhibit the diffusion of cadmium into fruits and seeds. Of all the wetland plants, the most cadmium was concentrated in the leaves of Zephyranthes Candida and P. cordata (Table 2). However, the stem-leaf transport coefficient of the latter was greater than 1, but its total amount of adsorped cadmium was only half of the former. It can be concluded that the cadmium transport rate of Zephyranthes Candida is faster than that of the other three cadmium enrichment plants, while the cadmium tolerance of Zephyranthes Candida was poor. Although the TF2 of $A$. donax was larger than 1, its cadmium absorption amount was much lower, indicating the plant has evolved a relatively complete defense mechanism to avoid adsorbing a large amount of cadmium from the environment and accumulating cadmium in its stems. As a result, the fruits, leaves, and seeds are less polluted.
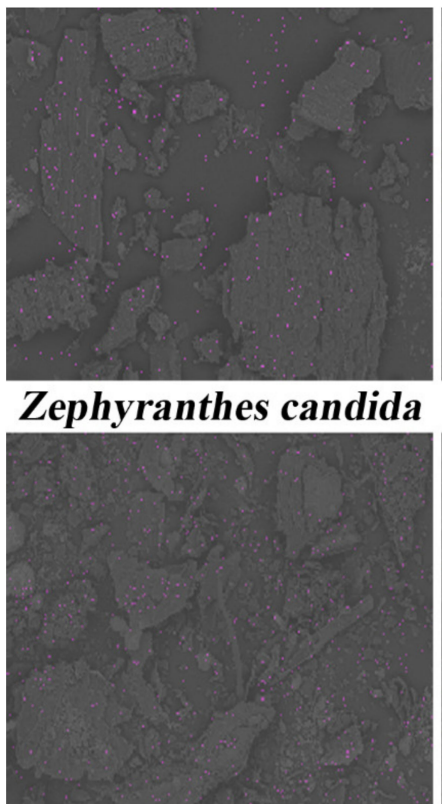

Phragmites communis

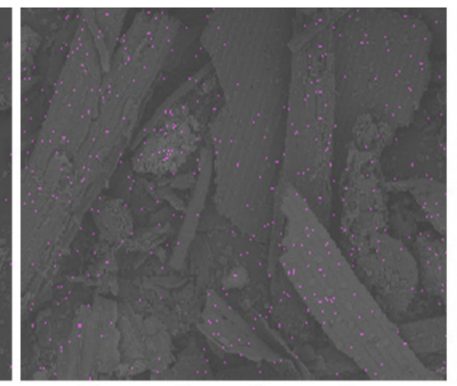

Cynodon dactylon

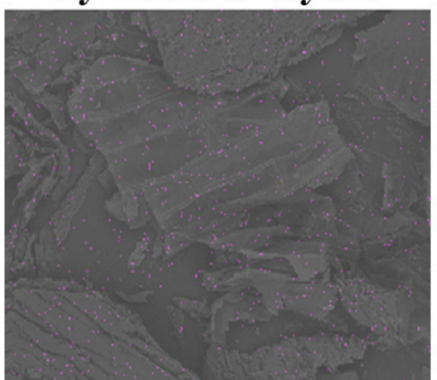

Pontederia cordata

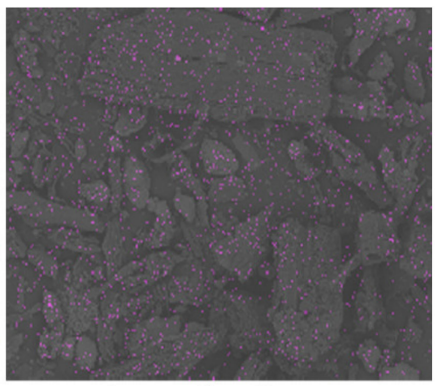

Arundo donax

Figure 2. Distribution of cadmium in different plants by SEM-EDS (The pink dots represent the distribution of cadmium).

Table 2. Accumulated cadmium concentration of five wetland plants.

\begin{tabular}{|c|c|c|c|c|c|c|c|c|}
\hline Plant & $\begin{array}{l}\text { Root } \\
\text { (PPM) }\end{array}$ & $\begin{array}{l}\text { Stem } \\
\text { (PPM) }\end{array}$ & Leaf (PPM) & $\begin{array}{c}\text { Total Absorption } \\
\text { (PPM) }\end{array}$ & $\begin{array}{l}\text { Background } \\
\text { Value (mg/kg) }\end{array}$ & BCF & TF1 & TF2 \\
\hline Zephyranthes candida & 0.013 & 0.036 & 0.024 & 0.073 & 1.602 & 1.62 & 2.77 & 0.67 \\
\hline Cynodon dactylon & 0.016 & 0.017 & 0.008 & 0.041 & 1.602 & 2.00 & 1.06 & 0.47 \\
\hline Arundo donax & 0.013 & 0.011 & 0.017 & 0.041 & 1.602 & 1.62 & 0.85 & 1.55 \\
\hline Phragmites communis & 0.005 & 0.011 & 0.006 & 0.022 & 1.602 & 0.62 & 2.2 & 0.55 \\
\hline Pontederia cordata & 0.01 & 0.016 & 0.021 & 0.047 & 1.602 & 1.25 & 1.6 & 1.31 \\
\hline
\end{tabular}

Note: the background value is taken from Zeng et al. [11,12]. 
Table 3. Stem and leaf size of five plants.

\begin{tabular}{ccc}
\hline Plants & Stem Diameter (CM) & Widest Part of Leaf (CM) \\
\hline Zephyranthes candida & 2.5 & 0.4 \\
Cynodon dactylon & 0.15 & 0.3 \\
Arundo donax & 3.5 & 5 \\
Phragmites communis & 4 & 2 \\
Pontederia cordata & 1 & 3 \\
\hline
\end{tabular}

\subsection{Reaction Mechanisms of Cadmium with Organic Compounds in the Subcellular Environment}

When cadmium reaches leaves, fruits, and other organs in the plant, physiological toxicity in the subcellular structure would be present. In order to verify the physiological toxicity of cadmium, the changes of the main organic compounds in the subcellular structure after cadmium contamination in chloroplasts and mitochondrion were calculated. It is worth noting that the original organic compounds have no electrons of $d$-orbitals, and it is easy for cadmium to form spd orbital hybrids with the original organic compounds after complexation with cadmium. Combined with Figure 3, the density of states (DOS) of the cadmium pyruvate at $\pm 5 \mathrm{eV}$ and cadmium gluconate at $5 \mathrm{eV}$ changed significantly, indicating the formation of orbital hybridization. According to the differential charge density of Figure 3 , the electron transport from the $d$-orbital of cadmium ion to the $s$ - and $p$-orbitals of hydroxyl oxygen is the reason for the formation of the new complex. As shown on the left side of Figure 3, once complexed with pyruvate and glucose, as an electron donor cadmium provided $0.05 \mathrm{eV}$ and $0.01 \mathrm{eV}$ charge. The charge was transported to hydroxyl oxygen. As shown on the right side of Figure 3, the density of states of pyruvate and glucose after cadmium complexation shift to the left side, indicating that the properties of the complex are relatively stable. For cadmium pyruvate, the maximum energy of the $p$-orbital electron is increased from $6 \mathrm{eV}$ to $8-10 \mathrm{eV}$, which indicates that cadmium pyruvate has a higher reactivity. However, the highest energies of $s$ - and $p$ - orbitals were respectively excited from $7 \mathrm{eV}$ and $9 \mathrm{eV}$ to $10 \mathrm{eV}$. The overall reactivity of the compound was enhanced and changed significantly. Using calculations, it has been confirmed that cadmium ions can contaminate pyruvate and glucose in the mitochondria by orbital hybridization. The pyruvate and glucose contaminated by cadmium will continue to participate in the metabolic process of cells, but the subsequent physiological process will be affected due to the change of electron energy distribution (density of states). Some research found that some plants have alternative respiration abilities to ensure normal respiration [64]. If the plants did not avoid using the contaminated glucose and the contaminated pyruvate, the glucose would flow to extracellular areas [65] and have an inhibition of growth leading to some morphology change, such as leaf area shrinkage and leaf chlorosis. However, most plants do not have alternative respiration abilities, thus the common respiratory process lesions are consistent with the calculation results. Meanwhile, the $30 \%$ electron activity enhancement may also explain the results of a previous study, that is, $\mathrm{Cd}$ could transport electrons to the electron donor, therefore meaning that the electron acceptor, some respiratory enzyme, cannot obtain electrons [44]. Furthermore, research also observed some important enzymes have a range of activity decline of $20-80 \%$ under a continued high concentration of Cd stress [66].

$\mathrm{Mg}^{2+}$ in the center of chlorophyll A and chlorophyll B molecular structure is prone to replacement by a copper substitution reaction, which could change the properties of chlorophyll and affect the normal photosynthesis of plants. As shown in Figure 4, after $\mathrm{Mg}^{2+}$ replacement with $\mathrm{Cd}^{2+}$, the differential charge density indicates that $\mathrm{Cd}^{2+}$ transports $0.01 \mathrm{eV}$ charge to the surrounding four $\mathrm{N}$ atoms. Unlike cadmium pyruvate and cadmium glucose after cadmium doping, the PDOS suggest that there is no spd orbital hybridization since the energy peak and shape of $s$ - and $p$ - orbitals do not change significantly. When $\mathrm{Mg}^{2+}$ is replaced by $\mathrm{Cd}^{2+}$, the $s$-orbital electrons of chlorophyll are excited, and the peak energy of $s$-orbital at $-40 \mathrm{eV}$ disappears. According to the energy-band theory, the s-orbital electrons of chlorophyll contaminated by cadmium could become more concentrated, making some cadmium appear in the deeper s-orbital electron valence band and excite the 
higher-energy valence band. However, the electron energy of the rest of the $s$ - and $p$-orbitals did not show distinct shift and peak changes, which indicated that $\mathrm{Mg}^{2+}$ determined the $s$-orbital at $40 \mathrm{eV}$ of chlorophyll, and that the structure of chlorophyll may become much more unstable due to the substitution of $\mathrm{Cd}^{2+}$. The essence of chemical reactions is the interactions between electrons. It is possible that due to the lack of electron activity at $-40 \mathrm{eV}$, cadmium-doped chlorophyll may not be able to participate in some subsequent physiological processes. Previous research found a spatial leaf heterogeneity of decreased PSII (a photosynthesis pathway) photochemistry in the early stage of Cd containment which later completely recovered [67]. We thought the early abnormal photosynthesis resulted from the Cd substitution. With respect to the reported study, the Noccaea caerulescens has a $\mathrm{Cd}$ defense ability so the subsequent photosynthesis turned to normal. For the five plants in our experiment, whether the Cd defense ability existed, the influence on photosynthesis is certain. Another example is that a strong reduction in the maximum photochemical efficiency of PSII was observed [68]. It perhaps resulted from the fact that the chlorophyll-cadmium compounds are unstable and the valence electrons disappear at $-40 \mathrm{eV}$.
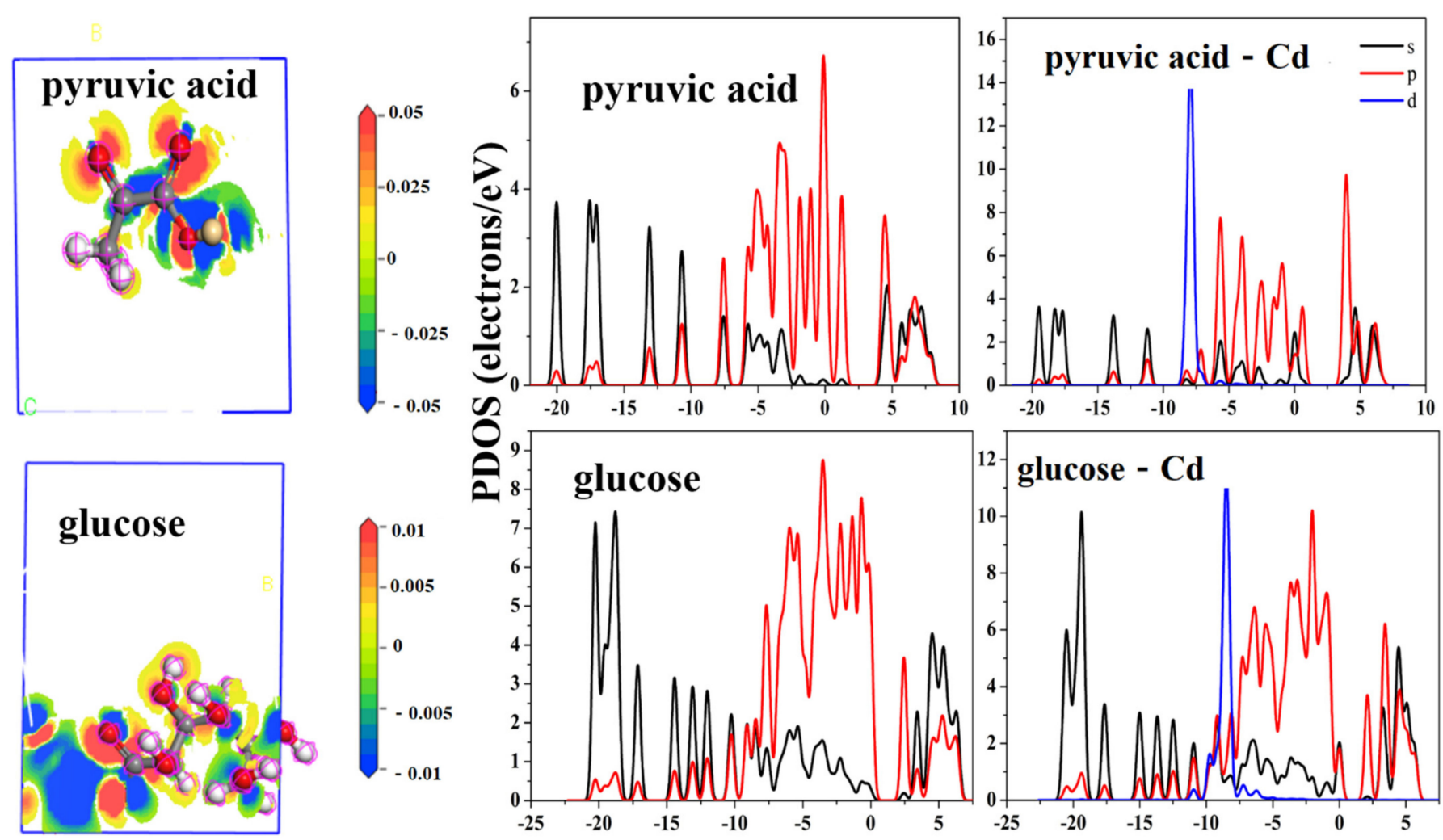

\section{Different Charge Density}

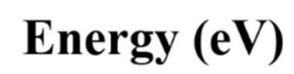

Figure 3. Reaction mechanisms of cadmium with mitochondrial components. 


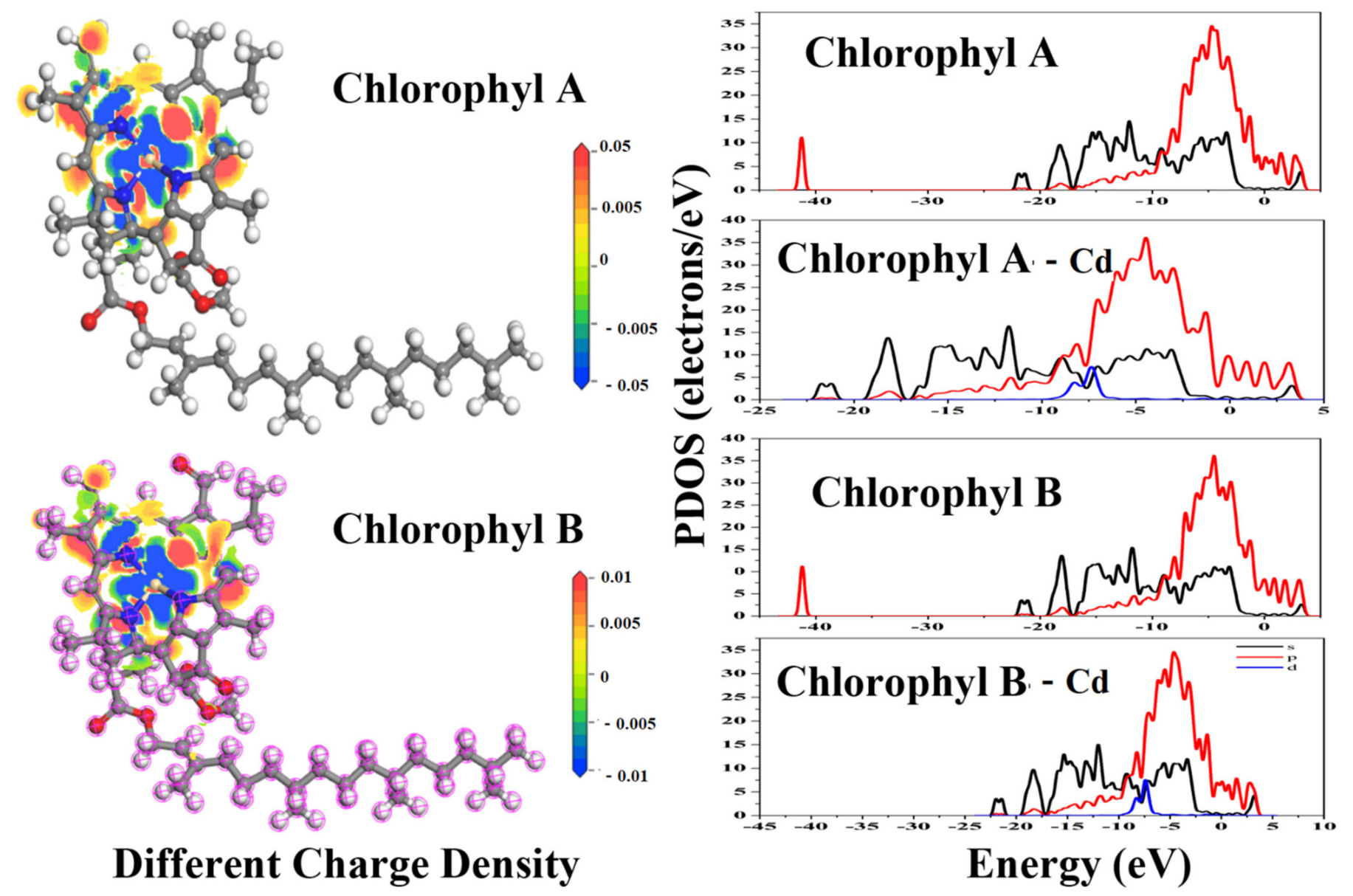

Figure 4. Reaction mechanism between cadmium and chloroplast components.

\section{Conclusions}

Considering the increasing cadmium pollution in water and soil in Southwest China, five wetland plants were collected from the constructed wetland in the upper reaches of the Yangtze River, namely the Tuojiang River. Various experiments and simulations were performed to reveal cadmium absorption from the environment by plants, the efficiency of cadmium accumulation and transport in plants, as well as the effects of cadmium on physiological processes in the subcellular structure. According to the experimental results, the order of cadmium absorption is Z. candida $>P$. cordata $>C$. dactylon $=A$. donax $>P$. communis. There were obvious differences in the absorption capacity among the five wetland plants, particularly between $P$. communis and the other four plants: the absorption capacity of $P$. communis for cadmium was lower compared to the rest of the plants. The transport coefficient of the stems and leaves of A. donax and P. cordata was more than 1 , suggesting poor tolerance to cadmium. Furthermore, cadmium was easily enriched in the leaves, fruits, and seeds of $P$. cordata.

By simulating the reaction energy barrier of root exudates with $\mathrm{Cd}, \mathrm{Ca}$, and $\mathrm{Fe}$, it was found that there was no obvious absorption advantage of the three metals; that is, $\mathrm{Cd}$ did not inhibit the entry of $\mathrm{Ca}$ and Fe into plants. Meanwhile, in the subcellular structure, it was found that $\mathrm{Cd}^{2+}$ could hybridize with the main materials of mitochondria, glucose, and pyruvate by providing $d$-orbital electrons. The peak energy of $s$ - and $p$ - orbitals increased by $30 \%$, the organic molecules became more unstable, and the reactivity increased. In the chloroplast, the substitution of $\mathrm{Mg}^{2+}$ by $\mathrm{Cd}^{2+}$ via a copper replacement reaction resulted in valence-electron vacancy at $-40 \mathrm{eV}$. As a result, the whole electron energy of chlorophyll became more concentrated, which reduced the stability of the molecular structure of chlorophyll. Thus, $\mathrm{Cd}^{2+}$ plays an important role in the subcellular structure since it could 
react with key organic compounds for the subsequent physiological process. However, from a quantum chemistry perspective, the underlying mechanisms are still unclear.

Nevertheless, the combination of experiment and DFT calculation methods used in this paper can provide data and method references for follow-up studies on pollutant absorption by plants, pollutant transport and reaction at the molecular level, as well as provide perspectives for related research.

Author Contributions: Conceptualization, Z.Z.; funding acquisition, Z.Z.; investigation, Z.Z., W.-G.L. and Z.W.; methodology, W.-G.L.; software, W.-G.L.; supervision, F.-C.Y.; writing-original draft, W.-G.L. All authors have read and agreed to the published version of the manuscript.

Funding: This study was supported by The National Key Research and Development Program of China, The R\&D And Model Construction Of Grading and Zoning Comprehensive Prevention And Control Technology System For Typical Non-Ferrous Metal Smelting Slag Field In Southwest China And Its Influence Area (SN: 2019YFC1803500); The National Key Research and Development Program of China, A Pollution Risk Assessment And Information Management Platform For The Influence Area Of Non-Ferrous Metal Smelting Slag Field (SN: 2019YFC1803504); The Key Research and Development Program of Sichuan Provincial Department of Science and Technology, Research Of The Development Of Heavy Metal Compound Pollution Passivator For Farmland Soil Based On Solid Waste Resource Utilization, Its Passivation Remediation Mechanism And The Effect Demonstration (SN: 2018SZ0298); The National Natural Science Foundation of China (No.41402248); The Open Fund Project of Sichuan Provincial Key Laboratory in Universities for the Development of Characteristic Biological Resources of Dry-hot River Valley, Study on the Assessment and In Situ Passivation Remediation of Heavy Metal Pollution of Soil Planted with Mango in Dry and Hot River Valley in Panzhihua (SN: GR-2020-E-02); Science and Technology Planning Project of Panzhihua, The Development Of A Pollution Assessment And Dynamic Monitoring System For Soil Heavy-Metal Pollution In Mango Main Producing Area In Panzhihua (SN: 2017CY-N-8); and The Longshan Talent Research Project of SWUST, The Assessment and Remediation of Soil Heavy Metal Pollution (SN: 17LZX613; 18LZX638).

Institutional Review Board Statement: Not applicable.

Informed Consent Statement: Not applicable.

Data Availability Statement: Not applicable.

Conflicts of Interest: The authors declare no conflict of interest.

\section{References}

1. Järup, L.; Åkesson, A. Current status of cadmium as an environmental health problem. Toxicol. Appl. Pharmacol. 2009, 238, 201-208. [CrossRef]

2. Nordberg, G.F. Historical perspectives on cadmium toxicology. Toxicol. Appl. Pharmacol. 2009, 238, 192-200. [CrossRef] [PubMed]

3. Joseph, P. Mechanisms of cadmium carcinogenesis. Toxicol. Appl. Pharmacol. 2009, 238, 272-279. [CrossRef]

4. De Araújo, R.P.; de Almeida, A.-A.F.; Pereira, L.S.; Mangabeira, P.A.; Souza, J.O.; Pirovani, C.P.; Ahnert, D.; Baligar, V.C. Photosynthetic, antioxidative, molecular and ultrastructural responses of young cacao plants to Cd toxicity in the soil. Ecotoxicol. Environ. Saf. 2017, 144, 148-157. [CrossRef]

5. Xu, P.; Zeng, G.; Huang, D.; Liu, L.; Zhao, M.; Lai, C.; Li, N.; Wei, Z.; Huang, C.; Zhang, C. Metal bioaccumulation, oxidative stress and antioxidant defenses in Phanerochaete chrysosporium response to Cd exposure. Ecol. Eng. 2016, 87, 150-156. [CrossRef]

6. Smeets, K.; Cuypers, A.; Lambrechts, A.; Semane, B.; Hoet, P.; Van Laere, A.; Vangronsveld, J. Induction of oxidative stress and antioxidative mechanisms in Phaseolus vulgaris after Cd application. Plant Physiol. Biochem. 2005, 43, 437-444. [CrossRef]

7. Feng, J.; Shi, Q.; Wang, X.; Wei, M.; Yang, F.; Xu, H. Silicon supplementation ameliorated the inhibition of photosynthesis and nitrate metabolism by cadmium (Cd) toxicity in Cucumis sativus L. Sci. Hortic. 2010, 123, 521-530. [CrossRef]

8. Yang, L.P.; Zhu, J.; Wang, P.; Zeng, J.; Tan, R.; Yang, Y.Z.; Liu, Z.M. Effect of Cd on growth, physiological response, Cd subcellular distribution and chemical forms of Koelreuteria paniculata. Ecotoxicol. Environ. Saf. 2018, 160, 10-18. [CrossRef] [PubMed]

9. Zhang, X.-F.; Hu, Z.-H.; Yan, T.-X.; Lu, R.-R.; Peng, C.-L.; Li, S.-S.; Jing, Y.-X. Arbuscular mycorrhizal fungi alleviate Cd phytotoxicity by altering Cd subcellular distribution and chemical forms in Zea mays. Ecotoxicol. Environ. Saf. 2019, 171, 352-360. [CrossRef] [PubMed]

10. Yang, X.; Lin, R.; Zhang, W.; Xu, Y.; Wei, X.; Zhuo, C.; Qin, J.; Li, H. Comparison of Cd subcellular distribution and Cd detoxification between low/high Cd-accumulative rice cultivars and sea rice. Ecotoxicol. Environ. Saf. 2019, 185, 109698. [CrossRef] 
11. Zeng, Z.; Luo, W.-G.; Wang, Z.; Yi, F.-C. Water Pollution and Its Causes in the Tuojiang River Basin, China: An Artificial Neural Network Analysis. Sustainability 2021, 13, 792. [CrossRef]

12. Zeng, Z.; Luo, W.-G.; Yi, F.-C.; Huang, F.-Y.; Wang, C.-X.; Zhang, Y.-P.; Cheng, Q.-Q.; Wang, Z. Horizontal Distribution of Cadmium in Urban Constructed Wetlands: A Case Study. Sustainability 2021, 13, 5381. [CrossRef]

13. Campbell, P.G.C.; Bisson, M.; Gagne, R.; Tessier, A. Critical evaluation of the copper(II) solubilization method for the determination of the complexation capacity of natural waters. Anal. Chem. 1977, 49, 2358-2363. [CrossRef]

14. Eriksson, J.E. The influence of $\mathrm{pH}$, soil type and time on adsorbtion and uptake by plants of Cd added to the soil. Water Air Soil Pollut. 1989, 48, 317-335. [CrossRef]

15. Li, F.; Okazaki, M.; Zhou, Q. Evaluation of Cd Uptake by Plants Estimated from Total Soil Cd, pH, and Organic Matter. Bull. Environ. Contam. Toxicol. 2003, 71,714-721. [CrossRef] [PubMed]

16. Eriksson, J.E. The effects of clay, organic matter and time on adsorption and plant uptake of cadmium added to the soil. Water Air Soil Pollut. 1988, 40, 359-373. [CrossRef]

17. Kwiatkowska-Malina, J. Functions of organic matter in polluted soils: The effect of organic amendments on phytoavailability of heavy metals. Appl. Soil Ecol. 2018, 123, 542-545. [CrossRef]

18. Hou, S.; Wang, X.; Shafi, M.; Penttinen, P.; Xu, W.; Ma, J.; Zhong, B.; Guo, J.; Xu, M.; Ye, Z.; et al. Remediation efficacy of Sedum plumbizincicola as affected by intercropping of landscape plants and oxalic acid in urban cadmium contaminated soil. J. Soils Sediments 2019, 19, 3512-3520. [CrossRef]

19. Javed, M.T.; Akram, M.S.; Tanwir, K.; Chaudhary, H.J.; Ali, Q.; Stoltz, E.; Lindberg, S. Cadmium spiked soil modulates root organic acids exudation and ionic contents of two differentially Cd tolerant maize ( Zea mays L.) cultivars. Ecotoxicol. Environ. Saf. 2017, 141, 216-225. [CrossRef]

20. Tao, Q.; Zhao, J.; Li, J.; Liu, Y.; Luo, J.; Yuan, S.; Li, B.; Li, Q.; Xu, Q.; Yu, X.; et al. Unique root exudate tartaric acid enhanced cadmium mobilization and uptake in Cd-hyperaccumulator Sedum alfredii. J. Hazard. Mater. 2020, 383, 121177. [CrossRef] [PubMed]

21. Huang, J.W.; Blaylock, M.J.; Kapulnik, Y.; Ensley, B.D. Phy-toremediation of uranium contaminated soils: Role of organ-icacids in triggering uranium hyper-accumulation in plants. Environ. Sci. Technol. 1998, 32, 2004-2008. [CrossRef]

22. Hazama, K.; Nagata, S.; Fujimori, T.; Yanagisawa, S.; Yoneyama, T. Concentrations of metals and potential metal-binding compounds and speciation of $\mathrm{Cd}, \mathrm{Zn}$ and $\mathrm{Cu}$ in phloem and xylem saps from castor bean plants (Ricinus communis) treated with four levels of cadmium. Physiol. Plant. 2014, 154, 243-255. [CrossRef]

23. Li, L.; Xiaohua, H.; Lianfu, T.; Xiaojun, D.; Manzhong, L.; Dongping, L.; Liangbi, C. Advances in mechanisms of plant uptake, transport and accumulation of cadmium. Plant Sci. 2015, 19, 176-184, (In Chinese with English abstract).

24. Chang, X.; Duan, C.; Wang, H. Root excretion and plant resistance to metal toxicity. Chin. J. Appl. Ecol. 2000, 11, 315-320. (In Chinese)

25. Hamon, R.; Wundke, J.; McLaughlin, M.; Naidu, R. Availability of zinc and cadmium to different plant species. Soil Res. 1997, 35, 1267-1278. [CrossRef]

26. Hussain, B.; Li, J.; Ma, Y.; Tahir, N.; Ullah, A. Effects of Fe and Mn cations on Cd uptake by rice plant in hydroponic culture experiment. PLoS ONE 2020, 15, e0243174. [CrossRef]

27. Ismael, M.A.; Elyamine, A.M.; Moussa, M.G.; Cai, M.; Zhao, X.; Hu, C. Cadmium in plants: Uptake, toxicity, and its interactions with selenium fertilizers. Metallomics 2019, 11, 255-277. [CrossRef]

28. Huang, R.; Dong, M.; Mao, P.; Zhuang, P.; Paz-Ferreiro, J.; Li, Y.; Li, Y.; Hu, X.; Netherway, P.; Li, Z. Evaluation of phytoremediation potential of five Cd (hyper) accumulators in two Cd contaminated soils. Sci. Total Environ. 2020, $721,137581$. [CrossRef] [PubMed]

29. Whiting, S.N.; Leake, J.R.; McGrath, S.P.; Baker, A.J. Positive responses to Zn and Cd by roots of the Zn and Cd hyperac-cumulator Thlaspi caerulescens. New Phytol. 2000, 145, 199-210. [CrossRef]

30. Krämer, U. Metal hyperaccumulation in plants. Annu. Rev. Plant Biol. 2010, 61, 517-534. [CrossRef]

31. Hart, J.J.; Welch, R.M.; Norvell, W.A.; Clarke, J.M.; Kochian, L.V. Zinc effects on cadmium accumulation and partitioning innear -isogenic lines of durum wheat that differ in grain cadmium concentration. New Phytol. 2005, 167, 391-401. [CrossRef] [PubMed]

32. Liu, X.; Peng, K.; Wang, A.; Lian, C.; Shen, Z. Cadmium accumulation and distribution in populations of Phytolacca americana L. and the role of transpiration. Chemosphere 2010, 78, 1136-1141. [CrossRef] [PubMed]

33. Yan, Y.F.; Choi, D.H.; Kim, D.S.; Lee, B.W. Absorption, translocation, and remobilization of cadmium supplied at different growth stages of rice. J. Agron. Crop Sci. 2010, 13, 113-119. [CrossRef]

34. Fujimaki, S.; Suzui, N.; Ishioka, N.S.; Kawachi, N.; Ito, S.; Chino, M.; Nakamura, S.I. Tracing cadmium from culture to spikelet: Noninvasive imaging and quan-titative characterization of absorption, transport, and accumulation of cadmium in an intact rice plant. Plant Physiol. 2010, 152, 1796-1806. [CrossRef] [PubMed]

35. Borges, K.L.R.; Salvato, F.; Alcântara, B.K.; Nalin, R.S.; Piotto, F.Â.; Azevedo, R.A. Temporal dynamic responses of roots in contrasting tomato genotypes to cadmium tolerance. Ecotoxicology 2018, 27, 245-258. [CrossRef] [PubMed]

36. Fattahi, B.; Arzani, K.; Souri, M.K.; Barzegar, M. Effects of cadmium and lead on seed germination, morphological traits, and essential oil composition of sweet basil (Ocimum basilicum L.). Ind. Crop. Prod. 2019, 138, 111584. [CrossRef]

37. Shah, V.; Daverey, A. Phytoremediation: A multidisciplinary approach to clean up heavy metal contaminated soil. Environ. Technol. Innov. 2020, 18, 100774. [CrossRef] 
38. Shanying, H.; Xiaoe, Y.; Zhenli, H.; Baligar, V.C. Morphological and physiological responses of plants to cadmium toxicity: A review. Pedosphere 2017, 27, 421-438.

39. Navarro-León, E.; Oviedo-Silva, J.; Ruiz, J.M.; Blasco, B. Possible role of HMA4a TILLING mutants of Brassica rapa in cadmium phytoremediation programs. Ecotoxicol. Environ. Saf. 2019, 180, 88-94. [CrossRef] [PubMed]

40. Mohamed, A.; Castagna, A.; Ranieri, A.; di Toppi, L.S. Cadmium tolerance in Brassica juncea roots and shoots is affected by antioxidant status and phytochelatin biosynthesis. Plant Physiol. Biochem. 2012, 57, 15-22. [CrossRef]

41. Meena, M.; Aamir, M.; Kumar, V.; Swapnil, P.; Upadhyay, R. Evaluation of morpho-physiological growth parameters of tomato in response to $\mathrm{Cd}$ induced toxicity and characterization of metal sensitive NRAMP3 transporter protein. Environ. Exp. Bot. 2018, 148, 144-167. [CrossRef]

42. Alyemeni, M.N.; Ahanger, M.A.; Wijaya, L.; Alam, P.; Bhardwaj, R.; Ahmad, P. Selenium mitigates cadmium-induced oxidative stress in tomato (Solanum lycopersicum L.) plants by modulating chlorophyll fluorescence, osmolyte accumulation, and antioxidant system. Protoplasma 2017, 255, 459-469. [CrossRef]

43. Sun, H.; Wang, X.; Shang, L.; Zhou, Z.; Wang, R. Cadmium accumulation and its effects on nutrient uptake and photo-synthetic performance in cucumber (Cucumis sativus L.). Philipp. Agric. Sci. 2017, 100, 263-270.

44. Ahmad, P.; Ahanger, M.A.; Alyemeni, M.N.; Wijaya, L.; Alam, P. Exogenous application of nitric oxide modulates osmolyte metabolism, antioxidants, enzymes of ascorbate-glutathione cycle and promotes growth under cadmium stress in toma-to. Protoplasma 2018, 255, 79-93. [CrossRef] [PubMed]

45. Dong, Y.J.; Chen, W.F.; Liu, F.Z.; Wan, Y.S. Physiological responses of peanut seedlings to exposure to low or high cadmium concentration and the alleviating effect of exogenous nitric oxide to high cadmium concentration stress. Plant Biosyst. Int. J. Deal. All Asp. Plant Biol. 2019, 154, 405-412. [CrossRef]

46. Vogel-Mikuš, K.; Arčon, I.; Kodre, A. Complexation of cadmium in seeds and vegetative tissues of the cadmium hyperaccumulator Thlaspi praecox as studied by $x$-ray absorption spectroscopy. Plant Soil 2010, 331, 439-451. [CrossRef]

47. Handy, N.C.; Lee, A. The adiabatic approximation. Chem. Phys. Lett. 1996, 252, 425-430. [CrossRef]

48. Echenique, P.; Alonso, J.L. A mathematical and computational review of Hartree-Fock SCF methods in Quantum Chemistry. Mol. Phys. 2007, 105, 3057-3098. [CrossRef]

49. Kolmanovich, V.; Reznik, I. Decompositions of electron density and the shell problem in Hohenberg-Kohn functional theory. Solid State Commun. 1984, 50, 117-120. [CrossRef]

50. Nagy, Á. Kohn-Sham equations for multiplets. Phys. Rev. A 1998, 57, 1672-1677. [CrossRef]

51. Cottenier, S. Density Functional Theory and the Family of $(L)$ APW-methods: A Step-by-Step Introduction; Instituut voor Kernen Stralingsfysica: Leuven, Belgium, 2002.

52. Jackson, K.; Pederson, M.R. Accurate forces in a local-orbital approach to the local-density approximation. Phys. Rev. B 1990, 42, 3276-3281. [CrossRef] [PubMed]

53. Perdew, J.P.; Yue, W. Erratum: Accurate and simple density functional for the electronic exchange energy: Generalized gradient approximation. Phys. Rev. B 1989, 40, 3399. [CrossRef]

54. $\mathrm{Wu}, \mathrm{H}$. Electronic structure study of double perovskites A2FeReO6(A = Ba, Sr, Ca)and Sr2MMoO6(M = Cr, Mn, Fe, Co) by LSDA and LSDA + U. Phys. Rev. B 2001, 64. [CrossRef]

55. Cole, D.J.; Hine, N.D.M. Applications of large-scale density functional theory in biology. J. Phys. Condens. Matter 2016, $28,393001$. [CrossRef]

56. Li, X.; Kou, Z.; Xi, S.; Zang, W.; Yang, T.; Zhang, L.; Wang, J. Porous NiCo2S4/FeOOH nanowire arrays with rich sulfide/hydroxide interfaces enable high OER activity. Nano Energy 2020, 78, 105230. [CrossRef]

57. Bian, L.; Dong, F.-Q.; Song, M.-X.; Dong, H.-L.; Li, W.-M.; Duan, T.; Xu, J.-B.; Zhang, X.-Y. DFT and two-dimensional correlation analysis methods for evaluating the Pu3+-Pu4+ electronic transition of plutonium-doped zircon. J. Hazard. Mater. 2015, 294, 47-56. [CrossRef] [PubMed]

58. Bian, L.; Song, M.-X.; Dong, F.-Q.; Duan, T.; Xu, J.-B.; Li, W.-M.; Zhang, X.-Y. DFT and two-dimensional correlation analysis for evaluating the oxygen defect mechanism of low-density $4 \mathrm{f}$ (or 5f) elements interacting with Ca-Mt. RSC Adv. 2015, 5, 28601-28610. [CrossRef]

59. Bian, L.; Xu, J.-B.; Song, M.-X.; Dong, F.-Q.; Dong, H.-L.; Shi, F.-N.; Zhang, X.-Y.; Duan, T. First principles simulation of temperature dependent electronic transition of FM-AFM phase BFO. J. Mol. Model. 2015, 21, 1-10. [CrossRef] [PubMed]

60. Ueno, D.; Ma, J.F.; Iwashita, T.; Zhao, F.J.; McGrath, S.P. Identification of the form of Cd in the leaves of a superior Cd -accumulating ecotype of Thlaspi caerulescens using 113 Cd-NM. Planta 2005, 221, 928-936. [CrossRef] [PubMed]

61. McGrath, S.P.; Lombi, E.; Gray, C.W.; Caille, N.; Dunham, S.J.; Zhao, F.J. Field evalua-tion of Cd and Zn phytoextraction potential by the hyper accu-mulators Thlaspi caerulescens and Arabidops is halleri. Environ. Pollut. 2006, 141, 115-125. [CrossRef] [PubMed]

62. Cieśliński, G.; Van Rees, K.C.J.; Szmigielska, A.M.; Krishnamurti, G.S.R.; Huang, P.M. Low molecular weight organic acids in rhizosphere soils ofdurum wheat and their effect on cadmium biosaccumulation. Plant Soil 1998, 203, 109-117. [CrossRef]

63. Asati, A.; Pichhode, M.; Nikhil, K. Effect of Heavy Metals on Plants: An Overview. Int. J. Appl. Innov. Eng. Manag. 2016, 5, 56-66. [CrossRef]

64. Edwards, J.R.; Prozialeck, W.C. Cadmium, diabetes and chronic kidney disease. Toxicol. Appl. Pharmacol. 2009, 238, 289-293. [CrossRef] 
65. Keunen, E.; Jozefczak, M.; Remans, T.; Vangronsveld, J.; Cuypers, A. Alternative respiration as a primary defence during cadmium-induced mitochondrial oxidative challenge in Arabidopsis thaliana. Environ. Exp. Bot. 2013, 91, 63-73. [CrossRef]

66. Deswal, M.; Laura, J.S. Effect of heavy metals cadmium, nickel and lead on the seed germi-nation and early seedling growth of Pisum sativum. Res. J. Life Sci. 2018, 4, 368. [CrossRef]

67. Bayçu, G.; Moustaka, J.; Gevrek, N.; Moustakas, M. Chlorophyll Fluorescence Imaging Analysis for Elucidating the Mechanism of Photosystem II Acclimation to Cadmium Exposure in the Hyperaccumulating Plant Noccaea caerulescens. Materials 2018, 11, 2580. [CrossRef] [PubMed]

68. Dias, M.C.; Monteiro, M.; Moutinho-Pereira, J.; Correia, C.; Gonçalves, B.; Santos, C. Cadmium toxicity affects photosynthesis and plant growth at different levels. Acta Physiol. Plant 2013, 35, 1281-1289. [CrossRef] 